\title{
Highly Effective Stratified Hub-and-Spoke Non-Pharmaceutical Intervention Provides New Insight into the Prevention of COVID-19 Transmission
}

\author{
Hao Li ${ }^{1, *} ;$ George F. Gao
}

As of November 20, 2020, there have been $56,982,476$ confirmed cases of coronavirus disease 2019 (COVID-19) globally, with the death toll reaching $1,361,847$, as reported to the World Health Organization (WHO) (1). Given the multiple epicenters of the pandemic and mounting death toll, it is imperative to seek optimal alternative nonpharmaceutical interventions (NPIs) strategies from a broader, more integrated perspective to fully project the subsequent waves of the pandemic, as no specific viral inhibitors or vaccines are available at the moment.

Many studies have implicated the role of community-based transmission and case importation in modulating the transmission dynamics of COVID-19 virus (2-3). There are now many modeling analyses focusing on the optimization of NPIs to control COVID-19. Among these interventions, mask-wearing, social distancing, and lockdown suppression seem to be the most effective (4-8). So far, by implementing strict NPIs, China has been extremely successful. What should we do globally?

In a recent PNAS paper, $\mathrm{Li}$ et al. test an effective framework of global coordination to contain pandemic outbreaks by developing a mathematical model that incorporates two factors of COVID-19 transmission, i.e. climate seasonality and human movement into various NPIs scenarios and proposes a hub-and-spoke [Global Intervention Hub (GIH) and secondary highrisk areas] organization mode for intervention strategies (9). A total of 2,485,256 confirmed cases, accounting for $92.75 \%$ of the world's total, were selected from 59 high-risk areas in countries with distinct climates where more than 10,000 cumulative cases had been reported as of April 24, 2020. Two mechanisms, i.e. the climate-driven community transmissions and movement-modulated spatial diffusions, that were likely to shape the post-pandemic trajectory of COVID-19 were incorporated. In addition, a variety of scenarios featuring different strategies, intensities, and durations of intervention in community-based transmission and international travel were applied to the model. As shown from the pandemic data, the transmission risk and spread of infections could be modulated by local climate conditions and the flow of flights. Wintertime and the airline flow are positively correlated with the onset of the COVID-19 pandemic. In this study, five intervention strategies based on the mathematical model were applied and their effectiveness was evaluated. Impact was evaluated in terms of the proportion of clinical cases averted and the number of areas where the goal of effectively reducing the incidence to less than 10 cases per day could be achieved in advance as compared with the projection in the absence of interventions.

In this model, the hub-and-spoke NPIs, specifically 8 -week intensive intervention in the initial period among GIHs and subsequent 8-week intensive intervention among the secondary areas, resulted in a median of $88.02 \%$ (23.18\% to $98.25 \%$ ) fewer cases, with 46 areas achieving control of transmission in advance. This scenario was deemed to be the most promising strategy when compared with other strategies, such as the 2-week mild intervention that reduces community-based transmission and international travel by $20 \%$. This model projected that a median of $15.11 \%$ (90\% CI: $2.02 \%-20.92 \%$ ) of clinical cases could be averted, and when coupled with the accelerated reduction of incidence to less than 10 cases (taken as "the effective control") in 15 areas, the 12 -week mild intervention could avert a median of $52.44 \%(9.69 \%$ to $70.12 \%)$ cases and lead to effective control of transmission in 26 areas. Lifting to a moderate intensity for 12 weeks would lead to a median of $79.95 \%$ (19.89\% to $93.94 \%$ ) cases averted, accelerating the process of effective control in 42 areas. Based on this research, the 8-week intensive NPIs targeting the reduction of local transmissibility and international travel were efficient and effective.

This result showed three key points. First, the theory 
that seasonality of climate and international travel contributed significantly to the global transmission of COVID-19 was validated. Second, given that the huband-spoke organization of interventions, particularly 8week intensive intervention in GIHs or secondary high-risk areas, had resulted in a median of $87.02 \%$ $(13.41 \%$ to $98.23 \%)$ averted cases, it was proposed that such kind of collaboration should be launched in areas with a high density of population and international travel, followed by other high-risk areas. Third, considering both climate seasonality and the changes of human behaviors, the author demonstrated that global collaborations on prompt and intensive interventions were fundamental to flatten out the curves of COVID-19 cases. Against the background of the COVID-19 pandemic, taking a tiered intervention strategy of hub-and-spoke organization, where interventions were first implemented at GIHs followed by timely interventions in secondary high-risk areas, was believed to be able to integrate global efforts and effectively improve the global emergency response to COVID-19 and many other infectious diseases.

Regarding the negative impact of social and economic lockdowns (10), this research explored control approaches aimed at more rapidly and effectively controlling the pandemic spread in specific major international hubs, but failed to scientifically evaluate the negative impact of such approaches on the economy. The hub-and-spoke strategy provided an option for the decisionmakers of pandemic prevention and will be a functional one to alleviate the tremendous burden on public health and society. Based on the findings of this study, here we are calling for active community-level NPIs for the new wave of pandemic around the world. Though the pandemic is under effective control in China at the moment, the world still needs to act with better coordination.

doi: $10.46234 / \mathrm{ccdcw} 2020.263$
\# Corresponding author: Hao Li, lihao@chinacdc.cn.

${ }^{1}$ Chinese Center for Disease Control and Prevention, Beijing, China.

Submitted: December 08, 2020; Accepted: December 10, 2020

\section{REFERENCES}

1. WHO Director. General's opening remarks at the media briefing on COVID-19-20 November 2020. https://www.who.int/director-general/ speeches/detail/who-director-general-s-opening-remarks-at-the-mediabriefing-on-covid-19---20-november-2020. [2020-12-7].

2. Liu JY, Liao XJ, Qian S, Yuan J, Wang FX, Liu YX, et al. Community transmission of severe acute respiratory syndrome coronavirus 2, Shenzhen, China, 2020. Emerg Infect Dis 2020;26(6):1320-3. http://dx.doi.org/10.3201/eid2606.200239.

3. Gilbert M, Pullano G, Pinotti F, Valdano E, Poletto C, Boëlle PY, et al. Preparedness and vulnerability of African countries against importations of COVID-19: a modelling study. Lancet 2020;395(10227):871 - 7 . http://dx.doi.org/10.1016/S0140-6736(20)30411-6.

4. Flaxman S, Mishra S, Gandy A, Unwin JT, Mellan TA, Coupland H, et al. Estimating the effects of non-pharmaceutical interventions on COVID-19 in Europe. Nature 2020;584(7820):257-61. http://dx.doi.org/10.1038/s41586-020-2405-7.

5. Li RY, Pei S, Chen B, Song YM, Zhang T, Yang W, et al. Substantial undocumented infection facilitates the rapid dissemination of novel coronavirus (SARS-CoV-2). Science 2020;368(6490):489- 93. http://dx.doi.org/10.1126/science.abb3221.

6. Lai SJ, Ruktanonchai NW, Zhou LC, Prosper O, Luo W, Floyd JR, et al. Effect of non-pharmaceutical interventions to contain COVID-19 in China. Nature 2020;585(7825):410 - 3. http://dx.doi.org/10.1038/ s41586-020-2293-x.

7. Prem K, Liu Y, Russell TW, Kucharski AJ, Eggo RM, Davies N. The effect of control strategies to reduce social mixing on outcomes of the COVID-19 epidemic in Wuhan, China: a modelling study. Lancet Public Health 2020;5(5):e261 - 70. http://dx.doi.org/10.1016/S24682667(20)30073-6.

8. Jiang TX, Wang H, Gao GF, Jiang XM. Wearing face masks-the simple and effective way to block the infection source of COVID-19. China CDC Wkly 2020;2(16):268 - 9. http://dx.doi.org/10.46234/ ccdcw2020.069.

9. Li RY, Chen B, Zhang T, Ren ZH, Song YM, Xiao YX, et al. Global COVID-19 pandemic demands joint interventions for the suppression of future waves. Proc Natl Acad Sci USA 2020;117(42):26151 - 7 . http://dx.doi.org/10.1073/pnas.2012002117.

10. Guan DB, Wang DP, Hallegatte S, Davis SJ, Huo JW, Li SP, et al. Global supply-chain effects of COVID-19 control measures. Nat Hum Behav 2020;4(6):577 - 87. http://dx.doi.org/10.1038/s41562-0200896-8. 